\title{
Dexamethasone's Effect on Post-Rhinoplasty Periorbital Edema
}

\author{
Habib Merza \\ ENT, Head \& Neck Surgery Department, Salmaniya Medical Complex, Ministry of Health, Manama, Kingdom of Bahrain \\ Email: drhabibmerza@yahoo.com
}

How to cite this paper: Merza, H. (2021) Dexamethasone's Effect on Post-Rhinoplasty Periorbital Edema. International Journal of Otolaryngology and Head \& Neck Surgery, 10, 419-425.

https://doi.org/10.4236/ijohns.2021.105038

Received: July 26, 2021

Accepted: September 14, 2021

Published: September 17, 2021

Copyright (c) 2021 by author(s) and Scientific Research Publishing Inc. This work is licensed under the Creative Commons Attribution International License (CC BY 4.0).

http://creativecommons.org/licenses/by/4.0/ (c) (i) Open Access

\begin{abstract}
Introduction: The efficacy of dexamethasone in reducing periorbital edema and ecchymosis following rhinoplasty was investigated in a double-blind, randomized trial. Materials \& Methods: The study comprised fifty-four rhinoplasty patients who underwent open rhinoplasty surgery with tip modification, hump excision, and bilateral osteotomy and were divided into three groups: Group one: 18 patients: a single dosage of $8 \mathrm{mg}$ dexamethasone given at the start of the procedure. Group two: 18 patients: three $8 \mathrm{mg}$ dexamethasone doses given at the start of the procedure, then 24 and 48 hours afterwards. Group 3: a control group of 18 patients who were not given any medication. Result: In comparison to control group 3, there was a significant reduction in periorbital edema and ecchymosis in groups 1 and 2. Group 2 had less periorbital edema and ecchymosis at the end of the first postoperative week than group 1. Conclusion: Edema and ecchymosis were significantly reduced with dexamethasone administration in rhinoplasty with osteotomy. Use of three doses of dexamethasone can reduce edema and ecchymosis after rhinoplasty more than the single dose treatment during the first postoperative week.
\end{abstract}

\section{Keywords}

Ecchymosis, Periorbital Edema, Dexamethasone

\section{Introduction}

Rhinoplasty is challenging operation and patient satisfaction rates are lower compared to other cosmetic procedures [1]. During rhinoplasty surgery, ecchymosis and swelling around the eyeball affect the patient's aesthetic outcome and can cause dissatisfaction between the patient and the treating physician. Swelling around the orbit and ecchymosis can lead to impaired vision for 24 to 48 hours, 
and because the appearance of this bruise is similar to that of patients with trauma and fractures of the facial bones, it will cause fear and dissatisfaction of the patient and those around him. During standard rhinoplasty, an osteotomy can cause bruising and swelling around the eyeball due to damage to the angular arteries and periosteum [2]. The main purpose of prescribing steroids is to minimize bruising and swelling around the eyes.

Theoretically, the anti-inflammatory effect of glucocorticoids reduces vascular permeability and reduces swelling and exudate. Many authors in various cosmetic surgeries have pointed out the favorable effect of steroids in reducing bruising and swelling around the eyes.

We compared a group of steroid injection with a control group without steroid injection for bruising and swelling around the eye after rhinoplasty in a randomized double-blind study.

\section{Materials and Methods}

In this clinical study 54 participants were selected for rhinoplasty procedure, that the subjects were randomly divided into three equal groups. No patient had any history of diseases such as hypertension, heart disease, diabetes, or any records of smoking or alcohol drinking. Any patients used aspirin and ibuprofen and supplements prior to surgery were excluded. The patient and the surgeon were unaware of how to take the steroid until the end of the study (double-blind study). The operation was performed under general anesthesia by a senior surgeon in the same manner. In all patients, the dorsal part of the nasal hump was removed and a standard bilateral lateral osteotomy was performed without internal osteotomy. Subperiosteal tunnel was not formed during osteotomy. The equipment and techniques used were the same in all patients.

During the operation, the surgical time and bleeding amount and blood pressure were recorded for each patient. Blood loss as determined by gain in sponge's weight and gain in gauge weight represents the amount of blood loss. The blood measured in suction bottle is added to the increase in sponges and gauge weight to determine the total amount of blood loss during surgery.

Normally a nasal pack was performed at the end of the operation. No additional drugs were used for patients except general anesthesia. Group 1: single one doses of $8 \mathrm{mg}$ intravenous dexamethasone was injected at the beginning of the operation. Group 2: three $8 \mathrm{mg}$ dose intravenous dexamethasone was injected at the beginning of operation, then $24 \& 48$ hours after operation. Group 3: No dexamethasone was injected at the beginning and after the operation.

The degree of swelling and ecchymosis around the eyes was determined in the first 24 hours after surgery and on the second, fifth and seventh days. The mean score on the lower and upper eyelids was determined by scoring 1 to 4 based on the Modified Surgeon Periorbital Rating of Edema and Ecchymosis (SPREE) score which is showed in Image 1 \& Image 2 [3].

The data were analyzed using statistical software SPSS V.20. Data were analyzed 
using chi-square and Mann-Whitney U-test. The difference between data was considered significant at $\mathrm{p}<0.05$.

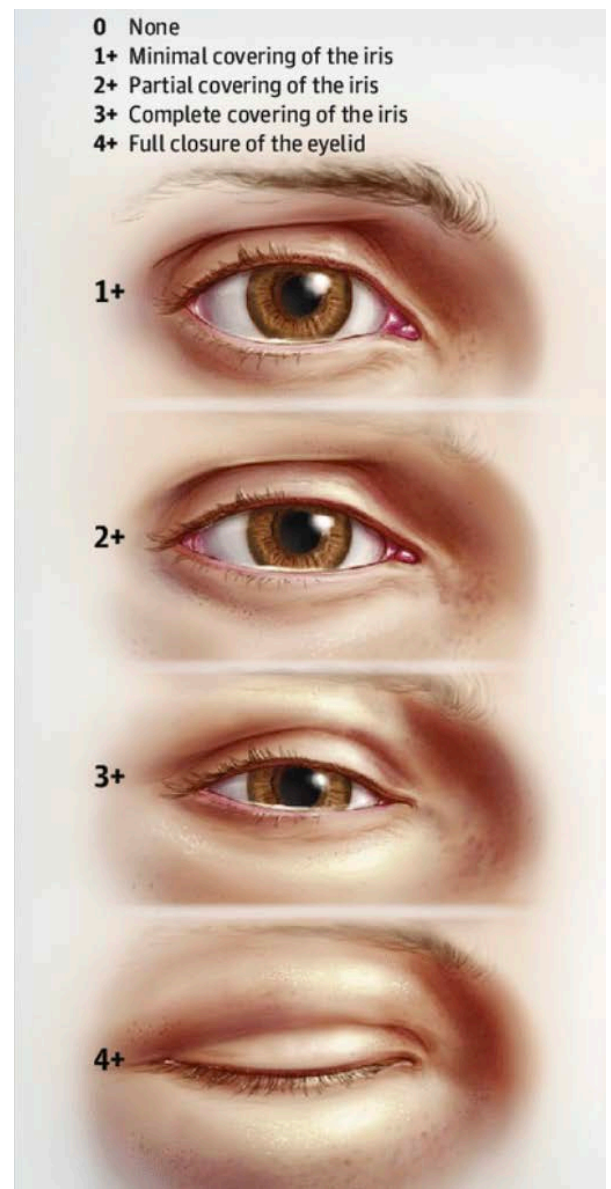

Image 1. Evaluation of eyelid edema. $0=$ None, $1+=$ Minimal of the iris, $2+=$ Partial covering of the iris, $3+=$ Complete covering of the iris, $4+=$ Full closure of the eyelid.

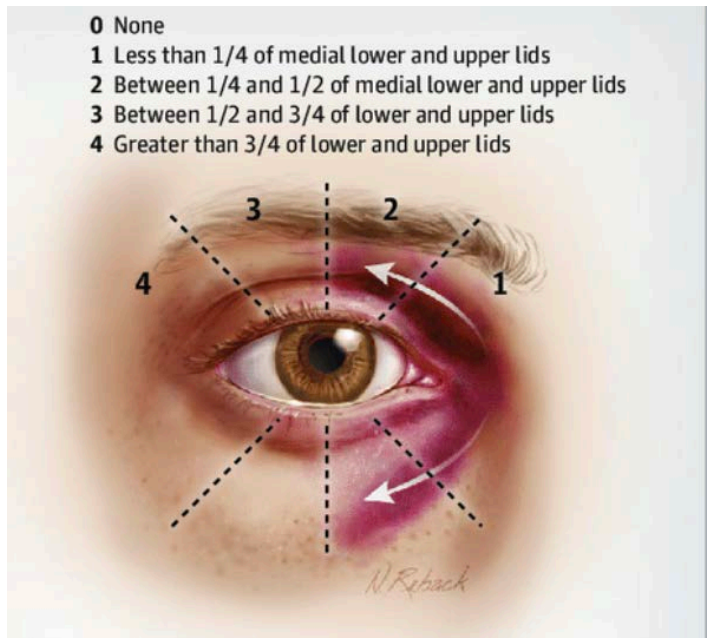

Image 2. Evaluation of the periorbital ecchymosis extension. $0=$ None, $1=$ Less than $1 / 4$ of medial lower and upper lids, $2=$ Between $1 / 4$ and $1 / 2$ of medial lower and upper lids, $3=$ Between $1 / 2$ and $3 / 4$ of lower and upper lids, $4=$ Greater than $3 / 4$ of lower and upper lids. 


\section{Results}

All surgical cases were open surgery. Fifty four patients underwent open rhinoplasty in which 18 were males (33\%) and 36 were females (67\%). The average age by the separation of sex was $21.95 \pm 3.52$ in men and was $22.26 \pm 3.95$ in women $(P=0.26)$. No statistically significant differences existed among the two groups in terms of sex $(\mathrm{p}=0.99)$. All the basic information is shown in Table 1.

In group 1, 2, who received dexamethasone, there was a marked reduction in bruising and swelling around the eye compared to group 3 ( $\mathrm{p}<0.0001)$. Also, group 2 patients who received three doses of dexamethasone showed more reduction in bruising and swelling around the eye compared to group 1 patients who received one single dose dexamethasone injection before operation $(\mathrm{p}<$ 0.0001 ) Figure $1 \&$ Figure 2.

No patient in the three groups had any complications from the prescription of dexamethasone.

\section{Discussion}

Bruising and swelling around the eyes are common in all face surgeries. To reduce this image, steroids with different doses have been used in different applications.

Table 1. Mean \pm SD of the results of three groups of patients following rhinoplasty.

\begin{tabular}{ccccc}
\hline Variables & $\begin{array}{c}\text { Group I } \\
(\mathrm{n}=18)\end{array}$ & $\begin{array}{c}\text { Groupe II } \\
(\mathrm{n}=18)\end{array}$ & $\begin{array}{c}\text { Groupe III } \\
(\mathrm{no}=18)\end{array}$ & P-value \\
\hline Age (year) & $22.25 \pm 4.12$ & $23.06 \pm 4.03$ & $22.57 \pm 3.86$ & 0.3 \\
Operation time (min) & $103.50 \pm 10.3$ & $100.20 \pm 6.28$ & $101.37 \pm 5.30$ & 0.28 \\
Systolic arterial pressure (mmHg) & $92.20 \pm 6.12$ & $91.5 \pm 5.8$ & $92.10 \pm 5.4$ & 0.62 \\
Diastolic arterial Pressure (mmHg) & $75.20 \pm 6.8$ & $74.30 \pm 5.6$ & $73.60 \pm 4.8$ & 0.23 \\
Amount of intraoperative bleeding $(\mathrm{ml})$ & $128.5 \pm 54.20$ & $96.30 \pm 62.20$ & $110.20 \pm 50.35$ & 0.85
\end{tabular}

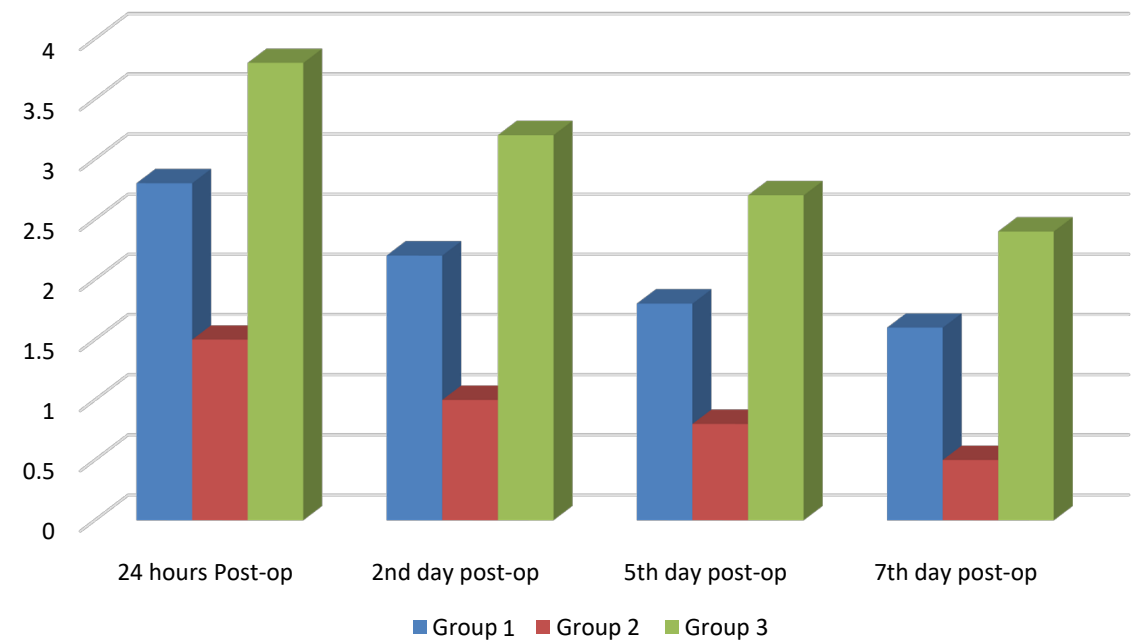

Figure 1 . The average severity of edema around the eyes in the different study groups. 


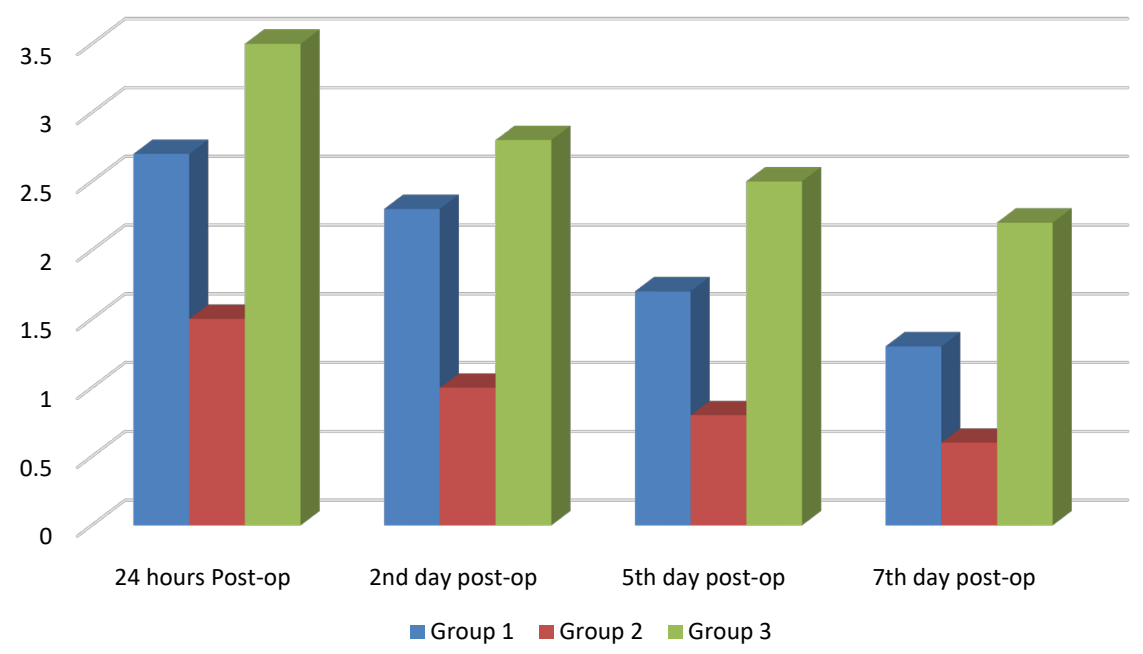

Figure 2. The average severity of ecchymosis around the eyes in the different study groups.

In the Habal and Powel study, facial swelling has been caused by coronal incisions and stripping of the face in pigs. After steroid administration, facial edema was lower in the steroid group in 24 and 48 hours after surgery, but have been the same after 72 hours with the control group [4].

Owsley designed a double-blind study that compared 30 patients after facelift surgery who took steroids postoperatively with a control group and did not see a significant difference [5].

Echvaez and Mangat examined the effects of steroids on the throat and swelling and ecchymosis. There was no significant difference between placebo and patients in terms of swelling and ecchymosis [6]. Although some studies have shown that steroids are not useful, other studies have proven its usefulness [7]. Facelift and other similar surgeries are associated only with manipulation of the soft tissues of the face, resulting in side effects such as edema and ecchymosis which will be less than rhinoplasty with osteotomy.

Kitel \& Masing, by injecting crystalloid containing corticosteroids into the soft tissue of 796 patients during rhinoplasty, found that the reduction of edema and ecchymosis around the eye in the first group was quite significant compared to 27 patients who underwent intramuscular injection of corticosteroids [8]. Their recommended drug was methylprednisolone, which causes a rapid reduction in edema on the first day after surgery.

Dexamethasone is potentially the most potent anti-inflammatory steroid, with a near-prolonged effect and a biological half-life of 36 to 54 hours [9]. Griffies injected a single $10 \mathrm{mg}$ dose of intravenous dexamethasone to 31 patients during double-blind rhinoplasty [10]. They found that steroid administration may reduce bleeding during surgery and reduce bruising and swelling 24 hours after surgery. In Gokalan et al. and Kargi et al. studies, the effect of a single dose of dexamethasone on postoperative edema and ecchymosis and bleeding during rhinoplasty was investigated [11] [12]. There was a clear difference between ste- 
roids and the control group in reducing the edema and ecchymosis of upper eyelid during the first two days but there was no change in the amount of edema of the lower eyelid and the amount of bleeding. In the single-dose steroid group in our study compare with the results obtained by Griffies, Gokalan and Kara's studies did not differ in the rate of swelling and bruising during the first 2 days.

Because dexamethasone has a half-life of 36 to 54 hours, we can maintain a good blood level by giving three doses for up to five days. Giving one dosage will not affect the reduction in edema and ecchymosis on the fifth day.

Tobin recommended taking $15 \mathrm{mg}$ of prednisolone before surgery and continuing it for two days after surgery [13]. Tobin's findings with this administration were comparable to the previous findings. Because it takes half an hour for an intravenous corticosteroid to take effect, we can inject it before having an osteotomy.

\section{Conclusion}

Use of dexamethasone injection in rhinoplasty with osteotomy is associated with a clear reduction of bruising and swelling around the eyes. According to the results, use of three doses of dexamethasone can reduce edema and ecchymosis after rhinoplasty with osteotomy more than the single dose treatment.

\section{Conflicts of Interest}

The author declares no conflicts of interest regarding the publication of this paper.

\section{References}

[1] Constantian, M.B. (2012) What Motivates Secondary Rhinoplasty? A Study of 150 Consecutive Patients. Plastic and Reconstructive Surgery, 1303, 667-678. https://doi.org/10.1097/PRS.0b013e31825dc301

[2] Byron, J. and Bailey, K.H. (2001) Calhoun Atlas of Otolaryngology, Head and Neck Surgery. 2nd Edition. Lippincott Williams and Wilkins, USA, 468.

[3] Oliver, J., Menapace, D., Younes, A., Recker, C., Hamilton, G. and Friedman, O. (2018) Validation of the Modified Surgeon Periorbital Rating of Edema and Ecchymosis (SPREE) Questionnaire: A Prospective Analysis of Facial Plastic and Reconstructive Surgery Procedures. Facial Plastic Surgery, 34, 95-101. https://doi.org/10.1055/s-0037-1615282

[4] Habal, M.B. and Powell, R.D. (1978) Experimental Facial Edema: Treatment with Methylprednisolone. Journal of Surgical Research, 24, 353-358. https://doi.org/10.1016/0022-4804(78)90026-4

[5] Owsley, J.Q., Weibel, T.J. and Adams, W.A. (1996) Does Steroid Medication Reduce Facial Edema Following Face-Lift Surgery? A Prospective, Randomized Study of 30 Consecutive Patients. Plastic and Reconstructive Surgery, 98, 1-6. https://doi.org/10.1097/00006534-199607000-00001

[6] Echavez, M.I. and Mangat, D.S. (1994) Effects of Steroids on Mood, Edema, and Ecchymosis in Facial Plastic Surgery. Archives of Otolaryngology-Head and Neck Surgery, 120, 1137-1141. https://doi.org/10.1001/archotol.1994.01880340077013

[7] Habal, M.B. (1985) Prevention of Postoperative Facial Edema with Steroids after Fa- 
cial Surgery. Aesthetic Plastic Surgery, 9, 69-71. https://doi.org/10.1007/BF01570331

[8] Kittel, H. and Masing, H. (1976) Corticosteroid Therapy in Rhinoplasty. Rhinology, 14, 163-166.

[9] Gilman, A.F., Rall, T.W., Nies, A.S., et al. (1990) Goodman and Gilman's. The Pharmacological Basis of Therapeutics. Eighth Edition, Pergamon Press, New York, $1442-1454$.

[10] Griffies, W.S., Kennedy, K., Gasser, C., et al. (1989) Steroids in Rhinoplasty. Laryngoscope, 99, 1161-1164. https://doi.org/10.1288/00005537-198911000-00010

[11] Kara, C.O. and Gokalan, I. (1999) Effects of Single-Dose Steroid Usage on Edema, Ecchymosis, and Intraoperative Bleeding in Rhinoplasty. Plastic and Reconstructive Surgery, 104, 2213-2218. https://doi.org/10.1097/00006534-199912000-00043

[12] Kargi, E., Nuter, M.H., Babucc, O.U. and Altunkaya, H. (2003) Effect of Steroids on Edema, Ecchymosis, and Intraoperative Bleeding in Rhinoplasty. Annals of Plastic Surgery, 51, 570-574. https://doi.org/10.1097/01.sap.0000095652.35806.c5

[13] Tobin, H.A. (1987) Operative Setting and Anesthesia. Otolaryngologic Clinics of North America, 20, 721-742. https://doi.org/10.1016/S0030-6665(20)31591-7 